\title{
Enhancement of Bone-Marrow-Derived Mesenchymal Stem Cell Angiogenic Capacity by NPWT for a Combinatorial Therapy to Promote Wound Healing with Large Defect
}

\author{
Kangquan Shou, Yahui Niu, Xun Zheng, Zhanjun Ma, Chao Jian, \\ Baiwen Qi, Xiang Hu, and Aixi Yu \\ Department of Orthopedics, Zhongnan Hospital of Wuhan University, Wuhan, Hubei 430071, China \\ Correspondence should be addressed to Aixi Yu; yuaixi@whu.edu.cn
}

Received 31 October 2016; Accepted 20 December 2016; Published 24 January 2017

Academic Editor: Subhas Gupta

Copyright ( $\odot 2017$ Kangquan Shou et al. This is an open access article distributed under the Creative Commons Attribution License, which permits unrestricted use, distribution, and reproduction in any medium, provided the original work is properly cited.

Poor viability of engrafted bone marrow mesenchymal stem cells (BMSCs) often hinders their application for wound healing, and the strategy of how to take full advantage of their angiogenic capacity within wounds still remains unclear. Negative pressure wound therapy (NPWT) has been demonstrated to be effective for enhancing wound healing, especially for the promotion of angiogenesis within wounds. Here we utilized combinatory strategy using the transplantation of BMSCs and NPWT to investigate whether this combinatory therapy could accelerate angiogenesis in wounds. In vitro, after 9-day culture, BMSCs proliferation significantly increased in NPWT group. Furthermore, NPWT induced their differentiation into the angiogenic related cells, which are indispensable for wound angiogenesis. In vivo, rat full-thickness cutaneous wounds treated with BMSCs combined with NPWT exhibited better viability of the cells and enhanced angiogenesis and maturation of functional blood vessels than did local BMSC injection or NPWT alone. Expression of angiogenesis markers (NG2, VEGF, CD31, and $\alpha$-SMA) was upregulated in wounds treated with combined BMSCs with NPWT. Our data suggest that NPWT may act as an inductive role to enhance BMSCs angiogenic capacity and this combinatorial therapy may serve as a simple but efficient clinical solution for complex wounds with large defects.

\section{Introduction}

The healing of large areas of full-thickness skin defects is a challenging clinical problem $[1,2]$. Optimum healing of a cutaneous wound requires an effective way to stimulate rapid angiogenesis because blood vessels are crucial for wound repair for delivering oxygen and nutrients to the host cells in the wounds [3]. More importantly, the formation of new blood vessels is fundamental to sustain the granulation formation, which is indispensable stage for wound healing [4].

Mesenchymal stem cells have been shown to play an important role in the healing of cutaneous wounds [5]. Ideally, after the dermal wounding, endogenous mesenchymal stem cells (MSC) will be mobilized into the circulation, homing into the wounded skin and eventually differentiating into skin cells [6]. Although extremity ischemia is a powerful stimulant for marrow stem cell recruitment, fewer progenitor cells were able to migrate to the ischemic wound [7]. As a result of that, allogeneic BM-MSCs derived from healthy donors have been used to treat diseases in humans [8]; however, their contribution to wound healing, especially their differentiation during the healing process, has not been fully understood. In addition, the poor viability and low levels of BMSCs engraftment often limit their therapeutic potential [9].

Currently, several reports have described the environmental factors, including physical forces and soluble factors, driving MSC differentiation toward endothelial cell line, which is helpful to angiogenesis [10]. Namely, their hypothesis was realized by creating shear force stimuli with exogenous growth factors such as vascular endothelial growth factor (VEGF), modifying MSCs to overexpress VEGF [11], or through addition of specific inhibitors, including simvastatin [12]. However, these strategies are considered as timeconsuming and relative expensive [13]. 
Negative pressure wound therapy (NPWT) is a promising treatment that has become widely adopted and applied for wound repair since its advent over 15 years ago [14]. It can function as a therapy to draw the wound together and provide stimulating micromechanical forces [15]. It has been proven to induce a granulation tissue response [16] and enhance the microvascular circulation within the wound [17]. Skin defects could exhibit positive response to NPWT treatment leading to healing with or without skin graft [18]. However, whether the NPWT could serve as a inductive factor to stimulate MSCs behaviors such as angiogenesis capacity still remains to be identified.

Several studies reported the application of negative pressure to influence the biological behavior of cells in vitro. Wilkes et al. designed a bioreactor to explore the effect of subatmospheric pressure upon the fibroblasts and observed changed morphology, thicker appearance, and organized actin cytoskeleton of cells [19]. Previously, we have proved that the inductive effect of NPWT $(-125 \mathrm{mmHg})$ on rat periosteum-derived mesenchymal stem cells osteogenic differentiation in a 3D fibrin matrix through a subatmospheric perfusion bioreactor [20]. However, to date, little is known about the effect of higher-intensity NPWT (e.g., $-150 \mathrm{mmHg}$ ) on bone-marrow-derived mesenchymal stem cells (BMSCs) differentiation into the cutaneous wound healing related cell types and the benefit for the accelerated angiogenesis during wound healing. Considering that the mechanical forces exerted by NPWT can serve as an advantageous therapy to induce gradient level of hypoxia within the wounds and BMSCs may behave as a positive reaction under this hypoxia microenvironment [21, 22], the feasibility of combined strategy using NPWT and transplantation of BMSCs is worth evaluating. In this study, we assessed NPWT effects on BMSCs viability and differentiation behavior in vitro under NPWT. Furthermore, we investigated the effect of this combinatorial therapy and whether it could serve as an efficient way to accelerate angiogenesis in an animal cutaneous wound model.

We hypothesized that NPWT would improve the viability of the BMSCs and induce BMSCs differentiation into the cutaneous tissue related cell types and enhance their angiogenic capacity, leading to an accelerated angiogenesis for wound healing and regeneration.

\section{Materials and Methods}

2.1. BMSCs Isolation, Culture, and Characterization. All the experimental procedures were according to the guidelines for the Care and Use of Laboratory Animals of the National Institutes of Health and approved by the Institutional Animal Care and Use Committee (IACUC) of Wuhan University.

Briefly, 3-week-old male Sprague-Dawley (SD) rats (Laboratory Animal Center of Wuhan University, China) were sacrificed, and the bone marrow was obtained by flushing the marrow cavity with complete BMSC culture medium containing low-glucose Dulbecco's modified Eagle's medium (LDMEM, Hyclone, USA) supplemented with $10 \%$ fetal bovine serum (FBS, Gibco, USA) and $1 \%$ penicillin-streptomycin (P/S, Invitrogen, USA). After centrifugation, the cells were resuspended and cultured at $37^{\circ} \mathrm{C}$ in $5 \% \mathrm{CO}_{2}$. Cells of 3-4 passages were used for the following experiments. BMSCs were characterized by flow cytometry analysis at the third passage. CD90 (Biolegend, USA), CD45 (Biolegend, USA), CD44 (Biolegend, USA), and CD31 (Affymetrix eBioscience, USA) were used to identify the surface marker of BMSCs.

2.2. In Vitro NPWT Treatment. For the NPWT group, cells were cultured in the flask at a pressure of $-150 \mathrm{mmHg}$ for 9 days. Briefly, BMSCs were seeded in the T25 $\left(25 \mathrm{~cm}^{2}\right)$ at $37^{\circ} \mathrm{C}$ in $5 \% \mathrm{CO}_{2}$ in incubator, and one needle was penetrated through the plug cap and inserted into the flask, and the end of the needle was connected to a vacuum pump (VSD Inc.) that generated continuously suction at continuous $-150 \mathrm{mmHg}$. The control group was maintained in a similar incubator and same device but without negative pressure.

2.3. Assessment of the Morphology, Viability, and Proliferation of BMSCs under NPWT. BMSCs cultured in the flask under NPWT or not were fixed in $4 \%$ paraformaldehyde (Aspen, China) for $1.5 \mathrm{~h}$ and stained with FITC-conjugated phalloidin (Yeasen, China) for $1 \mathrm{~h}$. Finally, samples were stained with diamidine-phenylindole-dihydrochloride (DAPI, Aspen, China) and analyzed with a confocal fluorescence microscope system (Leica SP2, Leica, Germany).

To evaluate cell proliferation under NPWT, on days 1, 3, 6, and 9 after NPWT treatment, a CCK- 8 assay was performed. BMSCs cultured with normal pressure served as control. To assess BMSCs viability and death under NPWT, a live/dead assay was performed. On days 1, 3, 6, and 9, the cells in the culture flask were incubated with $1 \mathrm{mM}$ calcein AM (Wako, Japan) for $1 \mathrm{~h}$ and then incubated with $1 \mathrm{ug} / \mathrm{mL}$ propidium iodide (PI, Invitrogen, USA) for $5 \mathrm{~min}$ at $37^{\circ} \mathrm{C}$. Next, the cells were imaged using a fluorescence microscopy (IX51, Olympus, Japan). Live cells stained green, whereas dead cells stained red.

2.4. Full-Cutaneous Skin Wound Healing Model. Male SD rats weighing 250-300 g were purchased from the Laboratory Animal Center of Wuhan University (China) in accordance with the Institutional Animal Care and Use Committee (IACUC) of Wuhan University.

Rats were randomly divided into four groups: sham, NPWT group, local BMSC injection, or BMSC + NPWT group ( $n=9$ in each group). On day 0 , animals were anesthetized with ketamine hydrochloride $(60 \mathrm{mg} / \mathrm{kg}$ body weight), and $35 \mathrm{~mm}$ full-thickness excisional wounds (including panniculus carnosus) were created on the disinfected and shaved backs of the rats. For the BMSCs injection group, $2.5 \times 10^{6}$ BMSCs were resuspended in $100 \mu \mathrm{L}$ PBS and injected intradermally at 12 equidistant points around the wound edge. For the NPWT group, the wounds were covered with a $3.5 \mathrm{~cm} \times 3.5 \mathrm{~cm}$ area of Duoderm foam (VSD Medical Technology Co. Ltd, Wuhan, Hubei, China) and then covered with a Vacuum Assisted Closure Device with a constant negative pressure values at continuous $-150 \mathrm{mmHg}$. The connecting tubes of VAC device were long enough to avoid affecting the ambulation or the routine life of animals 
TABLE 1: Criteria for histological scores of wounds. Criteria of scoring system for granulation tissue formation and wound maturity.

\begin{tabular}{lcc}
\hline Score & Granulation tissue formation & Wound maturity \\
\hline$(1)$ & No/minimal granulation tissue & Limited cells present or highly inflammatory \\
$(2)$ & Low granulation tissue & Predominantly inflammatory \\
$(3)$ & Moderate granulation tissue & Equivalence between inflammatory and proliferative \\
$(4)$ & Extensive granulation tissue & Predominantly proliferative \\
$(5)$ & Very extensive granulation tissue & Highly proliferative \\
\hline
\end{tabular}

TABLE 2: The primer sequences for each primer used in the real-time RT-PCR. The primer sequences and annealing temperature of CD31, $\alpha$-SMA, VEGF, NG2, and $\beta$-actin.

\begin{tabular}{lcc}
\hline Genes & Primer sequences & Annealing temperature $\left({ }^{\circ} \mathrm{C}\right)$ \\
\hline$\beta$-Actin & Forward: CGTTGACATCCGTAAAGACCTC & 58 \\
& Reverse: TAGGAGCCAGGGCAGTAATCT & 58 \\
CD31 & Forward: GATCTCCATCCTGTCGGGTAAC & \\
& Reverse: GTGTCATTCACGGTTTCTTCGT & 58 \\
$\alpha$-SMA & Forward: CAACCCCTATACAACCATCACAC & 58 \\
VEGF & Reverse: CCCAAACTGCTTGCGTAACC & 58 \\
& Forward: ATCTTCAAGCCGTCCTGTGTG & 58 \\
\hline
\end{tabular}

such as eating and drinking. For the BMSC + NPWT group, the cells injection were the same as the BMSCs injection group, and then the NPWT were applied as described before. For the sham group, no treatment was performed except for generation of the full-thickness excisional wound. Finally, all of the wounds were covered with a semipermeable membrane (VSD Medical Technology Co, Ltd, Wuhan, Hubei, China) to prevent leakage and drying. All of the animals were housed individually. Using the same procedures, a new dressing was applied every 3 days in all groups.

On days $0,3,6$, and 9 after operation, the wounds were photographed and wound tissues were harvested. For histological analysis, the harvested specimens were immediately snap-frozen in Optimal Cutting Temperature compound (OCT compound) (Sakura Finetek, Torrance, CA) or fixed in $4 \%$ paraformaldehyde overnight and embedded in paraffin for hematoxylin and eosin (H\&E) staining and Masson's Trichrome staining and immunohistochemistry and immunofluorescence analyses.

The wound area was calculated using Image Pro Plus 6.0 (IPP 6.0) software (Media Cybernetics, USA). The calculation formula was performed as follows: (wound area on day 0 wound area day " $X$ ") $/($ wound area on day 0$) \times 100$. On day 9 , the formation of granulation tissue and wound maturity were assessed according to the reported scoring system based on the evaluation of the H\&E and Masson's Trichrome staining results [23] (Table 1).

2.5. Real-Time Quantitative PCR. BMSCs were cultured under NPWT or normal condition for 9 days. For in vivo RT-PCR, wound tissues harvest at indicated time points was stored at $-80^{\circ} \mathrm{C}$. Then, Total RNA was extracted via the TaKaRa MiniBEST Universal RNA Extraction Kit (Takara
Bio, Japan) following the manufacturer's instructions. cDNA was synthesized using the PrimeScript ${ }^{\mathrm{TM}}$ II First Strand cDNA Synthesis Kit according to the manufacturer's protocol (Takara Bio, Japan). PCR conditions comprised an initial step of denaturation for $1 \mathrm{~min}$ at $95^{\circ} \mathrm{C}$, followed by total 40 cycles of $15 \mathrm{~s}$ at $95^{\circ} \mathrm{C}, 20 \mathrm{~s}$ at $58^{\circ} \mathrm{C}$ and $20 \mathrm{~s}$ at $72^{\circ} \mathrm{C}$. After normalization against the housekeeping gene $\beta$-actin, the expression of genes of interest (shown in Table 2) was measured using the $2^{-\Delta \Delta \mathrm{Ct}}$ method.

2.6. Western Blotting Analyses. Total protein was isolated from BMSCs cultured under NPWT or normal condition or from wound tissues harvested at the indicated time points with a Total Protein Extraction Kit (Aspen, China). Equal amounts of protein from cells or tissue lysates were loaded onto a 5\% SDS polyacrylamide gel (Aspen, China) and transferred to a polyvinylidene fluoride (PVDF) membrane (Millipore, USA). Membranes were blocked with 5\% BSA in TBS and then incubated with primary antibodies against CD31 (1:500), $\alpha$-SMA $(1: 5000)$, VEGF (1:1000), NG2 $(1: 100)$, and $\beta$-actin $(1: 10,000$ for cell lysates and $1: 3000$ for tissue lysates) for overnight at $4^{\circ} \mathrm{C}$. Next, an HRPconjugated secondary antibody was applied $(1: 10,000)$ and detected with the Immobilon Western Chemiluminescent HRP Substrate system (Millipore, USA). All of the antibodies were purchased from Abcam Inc (United Kingdom).

2.7. Immunofluorescence. BMSCs cultured under NPWT or normal condition or the wound tissues on day 9 were fixed in $4 \%$ paraformaldehyde for $20 \mathrm{~min}$. For wound tissues, the samples were further embedded in paraffin and crosssectioned at $5 \mu \mathrm{m}$. Then, the samples were stained with primary antibodies against CD31 (1:100), $\alpha$-SMA (1:100), 

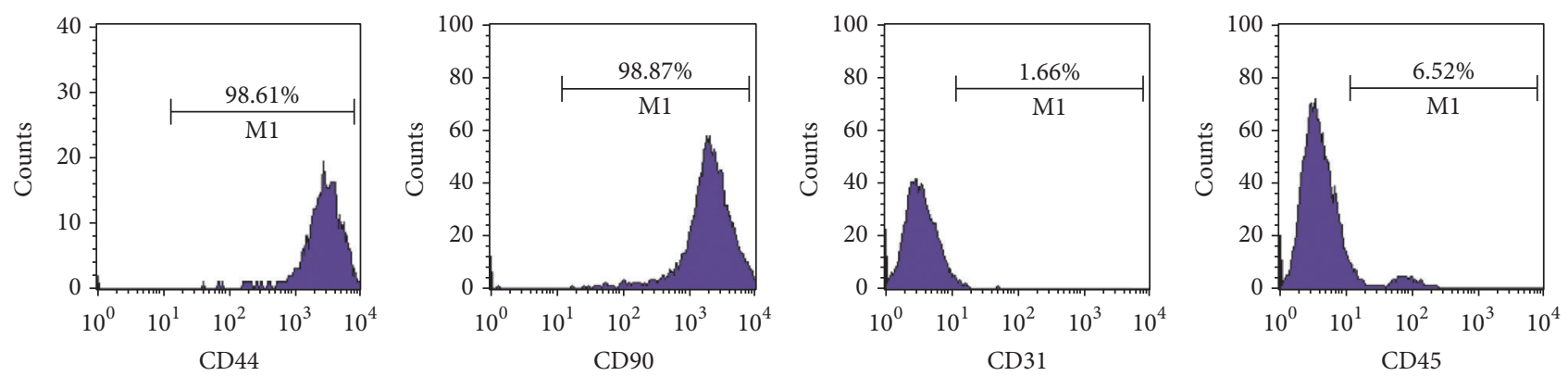

FIGURE 1: Characterization of BMSCs. Flow cytometry results of BMSCs at passage 3.

VEGF (1:200), and NG2 (1:50). After incubation with Cy3-conjugated secondary antibodies (1:50, Aspen, China), samples were added with DAPI to stain the cell nuclei.

2.8. Enzyme-Linked Immunosorbent Assay (ELISA). The concentrations of TGF- $\beta_{1}$ in the wound lysates on day 9 were measured by using ELISA from a Rat LAP Kit (TGF beta 1, Ready-SET-Go, Affymetrix eBioscience, USA), according to the manufacturer's instructions.

2.9. Assessment of Wound Vascularization. To assess blood vessel formation, immunohistochemistry was performed on day 6 . The tissue sections described above were incubated with primary antibodies (anti-collagen type IV, 1:100, and anti-CD31, 1:100, Abcam, United Kingdom) overnight at $4^{\circ} \mathrm{C}$ and then incubated with HRP-coupled secondary antibodies (Aspen, China). Staining was performed using diaminobenzidine (brown). For each section, tube-like structures were considered to be newly formed blood vessels and were quantified. Furthermore, to quantify the number of mature blood vessels, six sections from different tissue samples were selected from each treatment group for immunofluorescence analysis on day 9. CD31 (for endothelial cells), $\alpha$-SMA (for smooth muscle cells), and cell nuclei were stained red, green, and blue, respectively. Red and green costaining was considered to represent mature blood vessels. All of the evaluation procedures were performed independently by two pathologists.

2.10. Statistical Analysis. All of the values are expressed as mean \pm SD. Statistical significance between two groups was measured using the Student's unpaired $t$-test (two-tailed). The difference among different groups was detected using one-way analysis of variance (ANOVA) test. A $p$ value $<0.05$ was considered statistically significant.

\section{Results}

3.1. Characterization of Stem Cell Surface Markers of BMSCs. Cultured cells expressed CD44 (98.61\%) and CD90 (98.87\%) and did not express CD31 (1.66\%) and CD45 (6.52\%), demonstrating that the cells obtained from SD rats were BMSCs (Figure 1).
3.2. BMSCs Morphology, Viability, and Proliferation under NWPT. In comparison with standard culture (Figures 2(a) and 2(b)), BMSCs exhibited a spindle-shaped morphology under NPWT (Figure 2(d)). Of note, BMSCs cultured under NPWT maintained well viability (more than 76\%) for up to 9 days (Figures 2(c) and 2(e)). More importantly, BMSCs under NPWT exhibited slightly increased proliferation over seven days (Figure 2(f)).

3.3. Induction of BMSC Differentiation by NPWT. We examined different angiogenesis related cell markers including NG2 (for pericytes) and $\alpha$-SMA (for smooth muscle cells, SMCs); CD31 and VEGF (for endothelial cells, ECs) to represent the differentiation state of BMSCs. After 9 days of NPWT, the western blot results showed increased protein expression compared with the control group for NG2 $(0.3767 \pm 0.0328, p<0.001)$, VEGF $(0.7020 \pm 0.0344, p<$ $0.001)$, CD31 (0.8663 $\pm 0.0352, p<0.001)$, and $\alpha$-SMA $(0.8211 \pm 0.0351, p<0.001)$ (Figures 3(b) and 3(c)). Similarly, real-time qPCR analysis and immunofluorescence staining confirmed the same results as those observed in western blotting analyses (Figures 3(a) and 3(d)).

3.4. Wound Healing. Gross photographs of wound healing progression from each group in the cutaneous wound model were shown in Figure 4(a). Notably, wounds treated with BMSCs + NPWT showed accelerated healing at all time points compared with other treatment groups (Figure 4(b)). Specifically, there was remarkable acceleration of wound healing on day 9 in BMSC + NPWT group (37.15 $\pm 2.37 \%$, $p<0.001)$ compared with untreated wounds $(80.07 \pm 3.16 \%)$.

As shown in Figure 4(c), by using $\mathrm{H} \& \mathrm{E}$ and Masson's and picrosirius red staining, wounds treated with BMSC + NPWT exhibited abundant blood vessel distribution and increased collagen fibers aggregation in a regular arrangement, as compared with the local BMSC injection, NPWT, and sham groups.

3.5. Wound Vascularization. Using immunohistochemistry to explore CD31 expression, we observed abundant new blood vessels in BMSC + NPWT treated wounds but few in the sham group wounds on day $9(51.26 \pm 1.644$ vessels per $\mathrm{mm}^{2}$ versus $9.533 \pm 1.752$ vessels per $\mathrm{mm}^{2}, p<0.001$ ) 


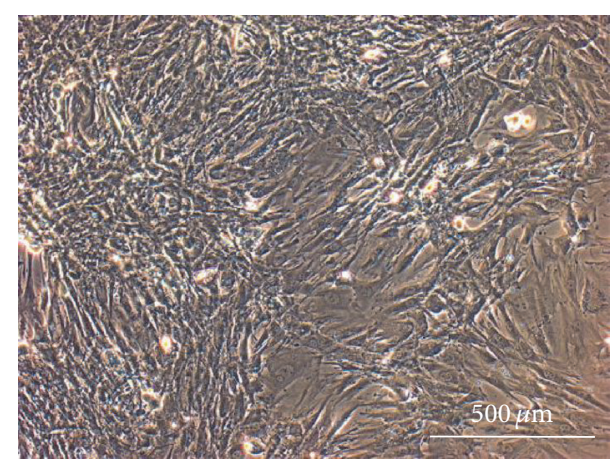

(a)

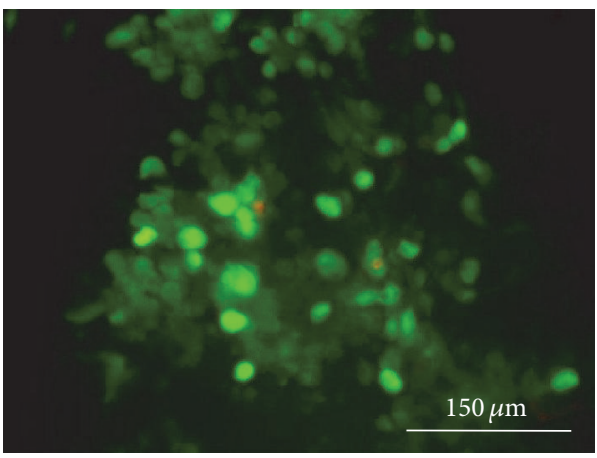

(c)

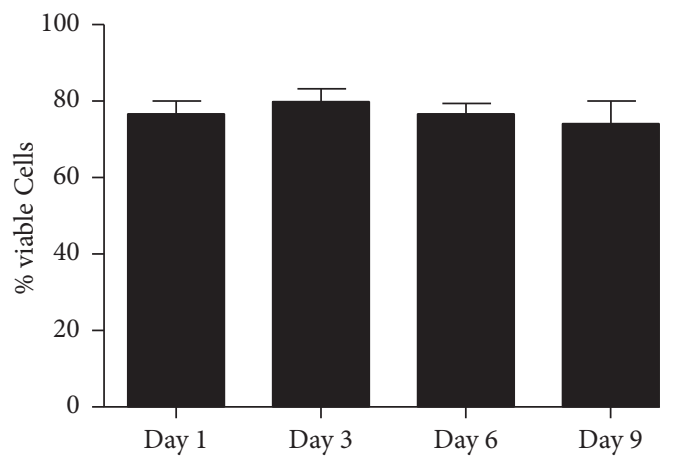

(e)

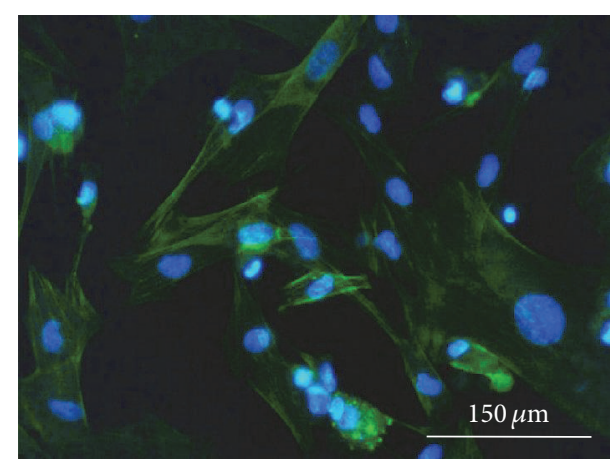

(b)

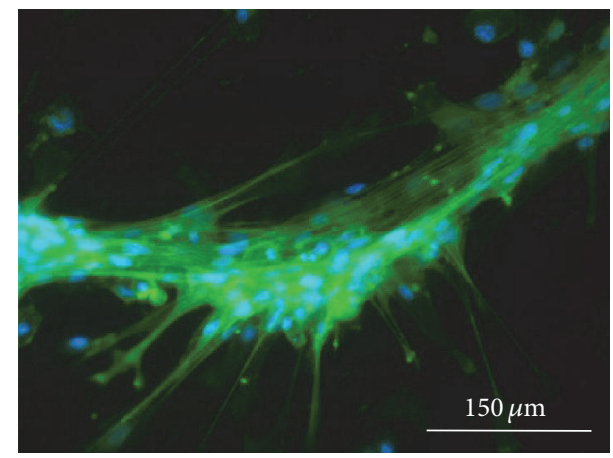

(d)

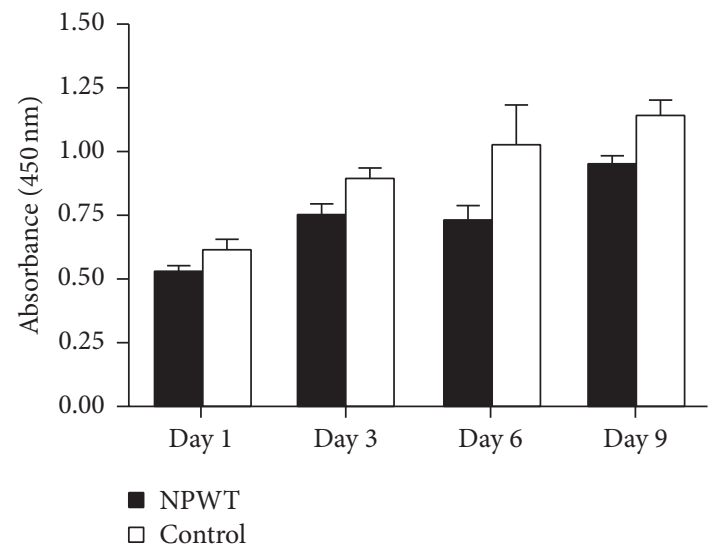

(f)

FIGURE 2: BMSCs morphology, viability, and proliferation under NWPT. (a) Light microscopy revealed morphology of BMSCs cultured in plates at 3 passage. (b) Fluorescent micrograph of BMSCs cultured in plates at 3 passages. (c) A representative image of live/dead assay at 9 days. Green: live cells, red: dead cells. (d) Fluorescent microscope image when BMSCs were cultured under NPWT. (e) The result of live/dead assay of BMSCs cultured under NPWT in vitro for 9 days. (f) An CCK-8 assay was used to assess proliferation of BMSCs with or without NPWT over 9 days. Data is given as the mean \pm SD.

(Figures 5(a) and 5(b)). Using immunohistochemistry to explore collagen IV expression, a well-developed vascular network was also present in the BMSC + NPWT-treated wounds at day 9 , whereas it was almost completely absent in sham group (Figures 5(a) and 5(c)).

Immunofluorescence costaining of CD 31 and $\alpha$-SMA representing mature blood vessels showed that BMSC + NPWT improved blood vessel maturity $(26.433 \pm 2.741$ vessels per $\left.\mathrm{mm}^{2}\right)$ compared with sham group $(3.530 \pm 1.741$ vessels per $\mathrm{mm}^{2}, p<0.001$ ) (Figures 6(a) and 6(b)).
In addition, granulation and wound maturity scores in the BMSC + NPWT group were both significantly higher than those in the sham groups $(p<0.001)$ (Figure 6(c)). As a primary driving factor responsible for angiogenesis process during granulation tissue formation, TGF- $\beta_{1}$ levels at all postwounding time points in wounds treated with BMSC + NPWT showed significantly higher concentrations than did untreated wounds $(p<0.001)$ (Figure 6(d)).

In addition, western blot analyses reflected enhanced NG2, CD31, VEGF, and $\alpha$-SMA protein levels in day 6 and 


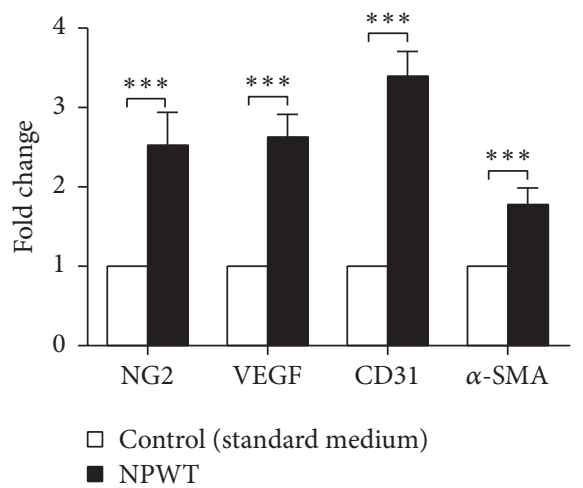

(a)
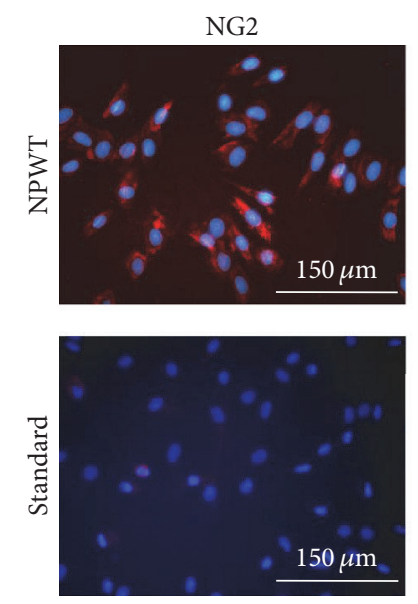

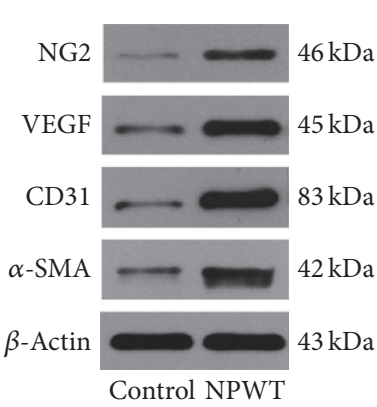

(b)

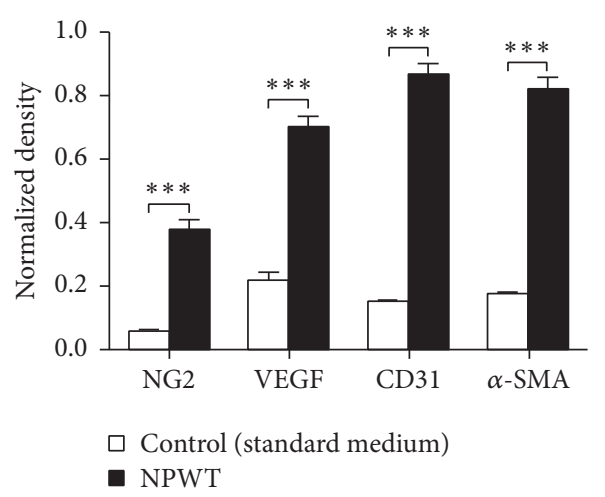

(c)
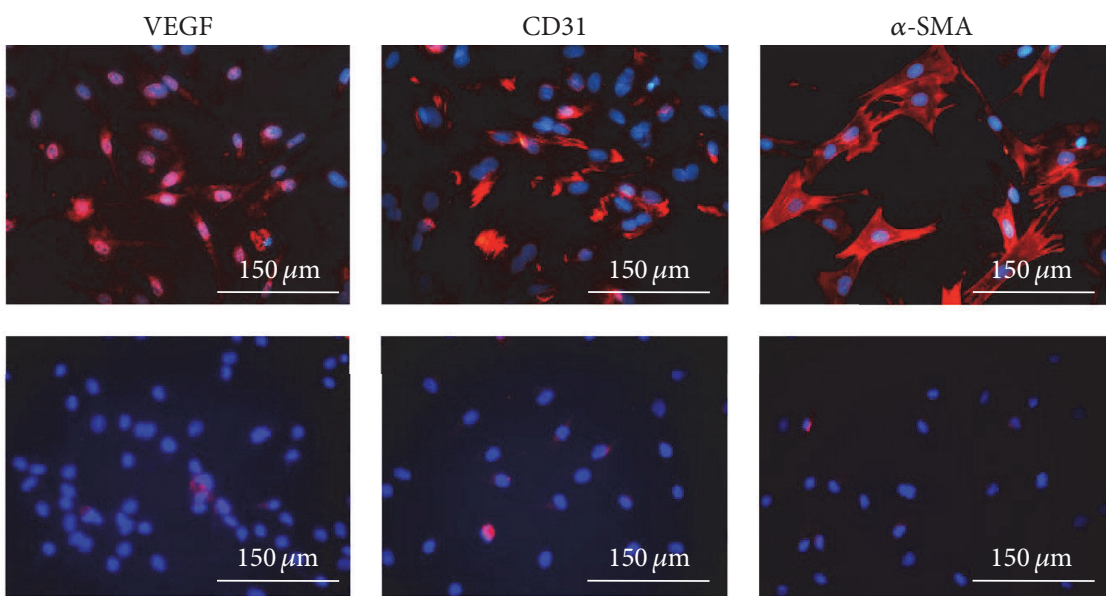

(d)

FIGURE 3: Effect of NPWT on BMSC differentiation. (a) qRT-PCR analysis of NG2, VEGF, CD31, and $\alpha$-SMA gene expression under NPWT versus $2 \mathrm{D}$ culture with standard medium. The data of 2D culture were considered as 1 . (b) Western blotting of NG2, VEGF, CD31, and $\alpha$-SMA protein expression under NPWT versus 2D culture. (c) Quantification of western blotting. (d) Immunofluorescent staining demonstrated that BMSCs cultured under NPWT exhibited differentiated states compared with $2 \mathrm{D}$ standard. Data is given as the mean $\pm \mathrm{SD},{ }^{* * *} p<0.001$.

9 wounds treated with BMSC + NPWT compared with untreated controls $(p<0.001$ ) (Figures 7(a), 7(b), 7(c), and $7(\mathrm{~d}))$. Real-time-PCR analysis and immunofluorescence staining also reflected the same tendency (Figures 7(e), 8(a), $8(\mathrm{~b}), 8(\mathrm{c})$, and $8(\mathrm{~d}))$.

\section{Discussion}

Our study investigated whether the combinatory strategy using BMSC injection coupled with NPWT can exert therapeutic effects in a murine cutaneous defect model and explored the underlying mechanisms involved. Our results demonstrated for the first time that BMSC + NPWT could significantly promote cutaneous wound healing, characterized by robust and enhanced vascularization at wound sites. Specifically, we have demonstrated that full thickness skin wounds treated with BMSCs combined with NPWT lead to acceleration of angiogenesis when compared to rats receiving topical administration of NPWT without stem cells. More importantly, we found that NPWT provided a beneficial microenvironment supporting better BMSC's viability and promoted their angiogenic capacity for abundant neoangiogenesis and maturation of blood vessels, suggesting that this strategy may serve as an alternative to aid fundamental soft tissue reconstruction for wound healing. Thus, a major challenge in regenerative medicine to create a functional microenvironment which supports and facilitates the angiogenic properties of BMSCs to enhance wound healing has been met, and this would further help to pave the way to clinical application.

During the past few years, negative pressure wound therapy (NPWT) has emerged as a treatment for those complex wounds that need effective therapy to heal. This method is the delivery of intermittent or continuous subatmospheric pressure through a particular pump, connecting to a poriferous and foam-surface dressing covered with an adhesive drape to maintain a vacuum environment [24]. Clinicians have consented that NPWT could stimulate a robust granulation tissue response compared with other available therapies [25-27]. But recently some different voice emerged, demonstrating that NPWT may prolong the healing time to wound closure and cause an increased need for skin grafts 

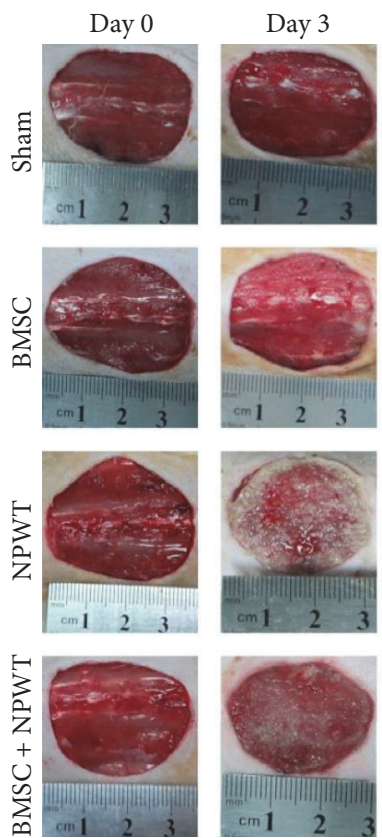

(a)
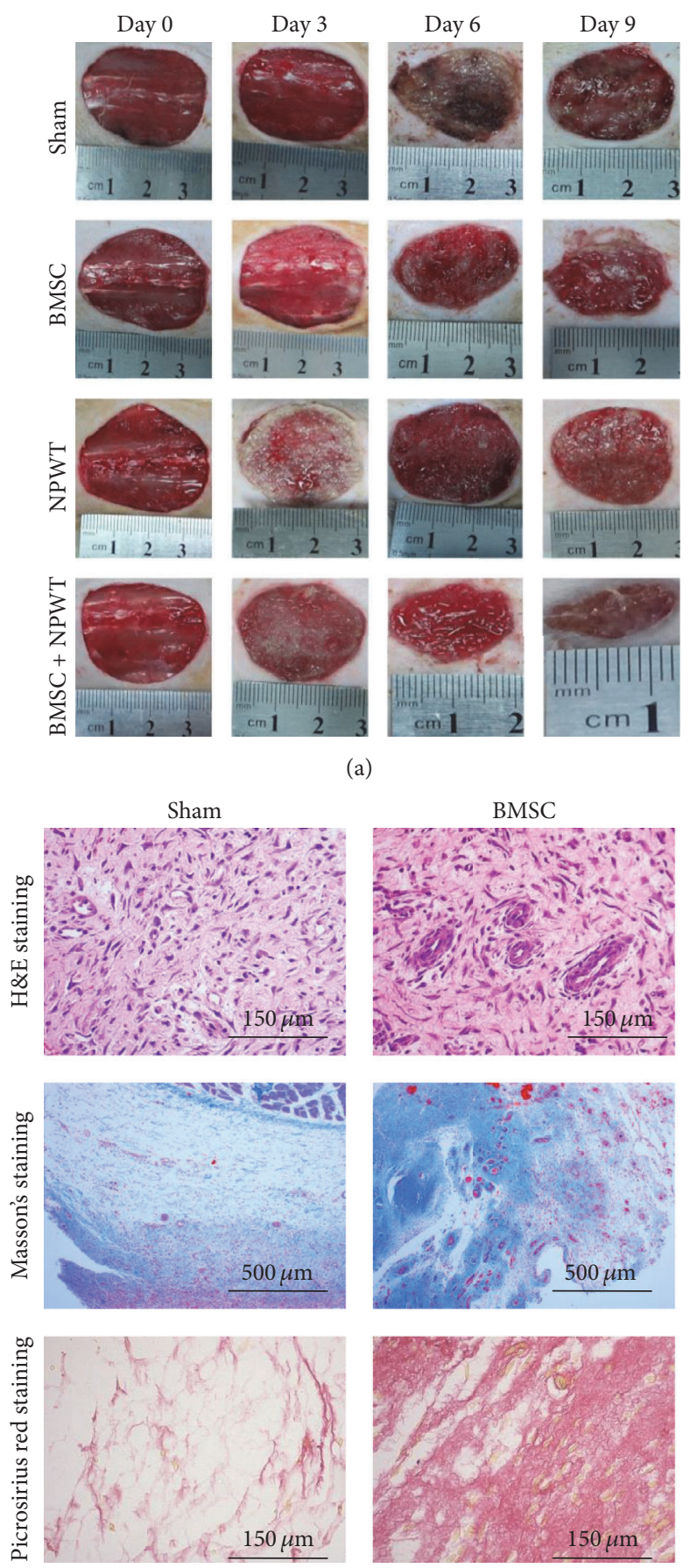

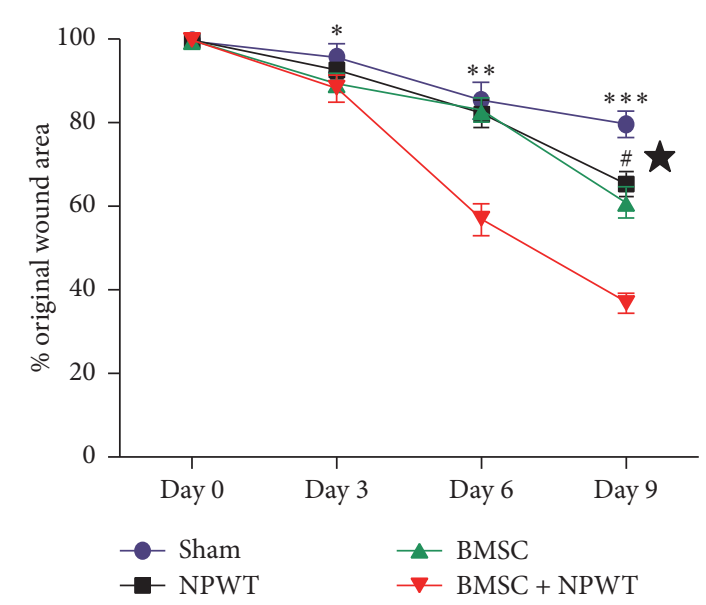

(b)
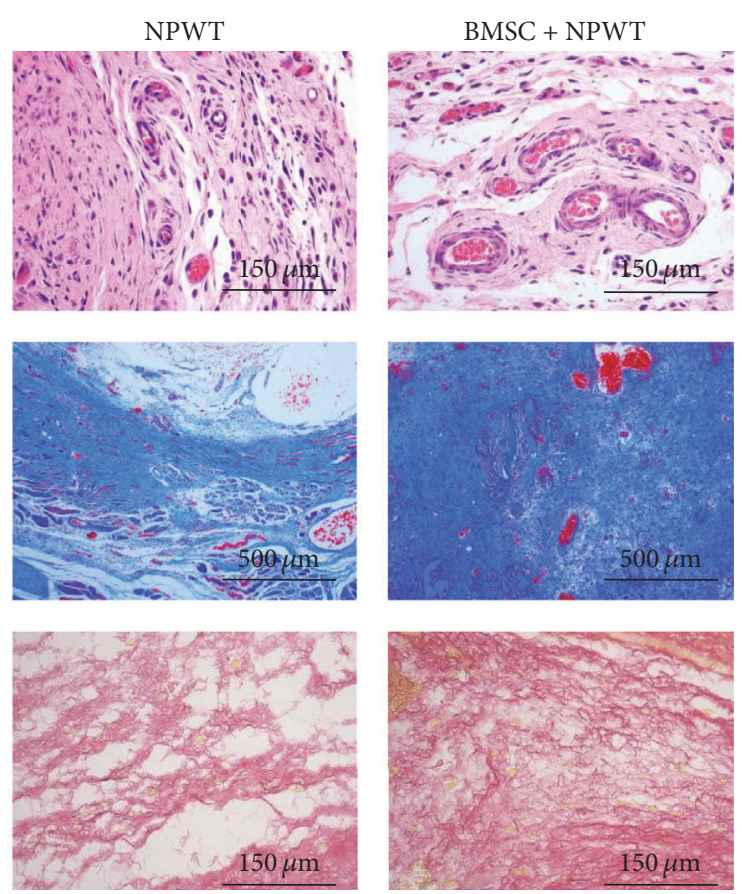

(c)

FIGURE 4: Evaluation of wound tissues. (a) Representative gross photos of the wounds treated with sham operation, BMSCs, NPWT, and BMSCs + NPWT. (b) Wound closure curves demonstrated significantly accelerated wound healing in BMSC + NPWT group. (c) H\&E staining, Masson's trichrome staining, and picrosirius red staining of wounds at day 9 . Data is given as the mean $\pm \mathrm{SD},{ }^{*} p<0.05,{ }^{* *} p<0.01$, and ${ }^{* * *} p<0.001$ untreated versus BMSC + NPWT at different time points, respectively; ${ }^{*} p<0.01$ NPWT versus BMSC + NPWT; ${ }^{\star} p<0.001$ local BMSC injection versus BMSC + NPWT.

for fasciotomy wounds [28]. Another experimental study demonstrated that there was a detrimental effect exerted by NPWT on the extent of muscle fiber regeneration on a pig model [29]. Therefore, a complementary therapy that can compensate the drawback of NPWT is worth evaluating.
Mesenchymal stem cells (MSC), which are recognized as pluripotent progenitor cells, have been proven to enhance tissue regeneration in several studies [30-32]. The effect of MSC transplantation to improve wound healing could be attributed to the inductive cell differentiation and the release 

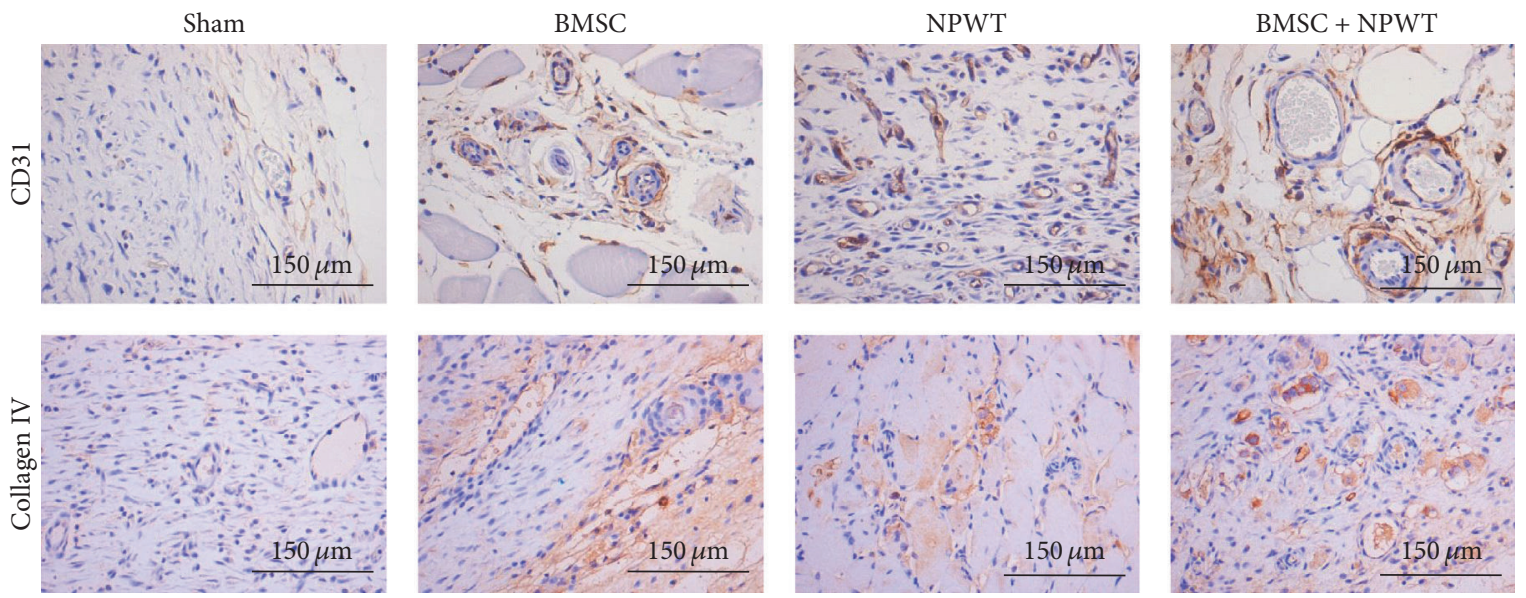

(a)

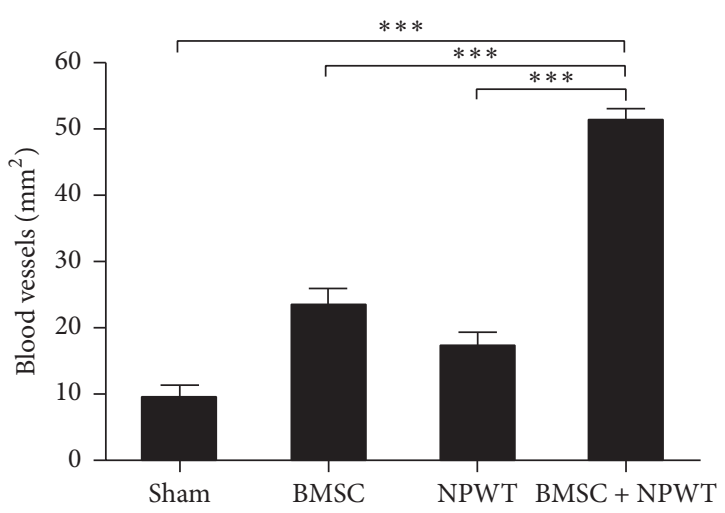

(b)

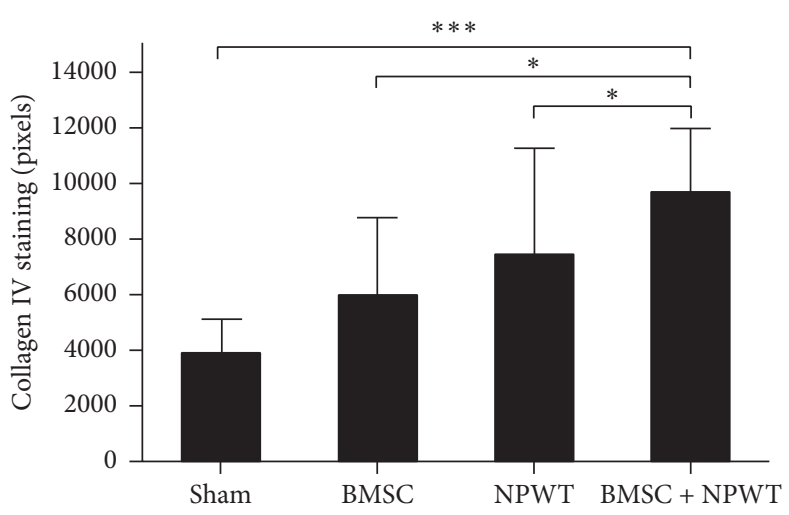

(c)

FIGURE 5: BMSC + NPWT accelerate the formation of vascularized granulation tissue. (a) Immunohistochemical staining for CD31 and collagen IV, representing newly formed blood vessels. (b) Quantification of newly formed blood vessels. (c) Quantification of collagen IV expression. Data is given as the mean $\pm \mathrm{SD},{ }^{*} p<0.05,{ }^{* * *} p<0.001$.

of paracrine factors from them. However, the poor viability of the engrafted MSC at the recipient site often impedes their therapeutic application. As a result of that, it is significant to increase the survival of transplanted MSC and enhance their biological functions such as secretion of factors.

Previously, we have demonstrated that negative pressure $(-125 \mathrm{mmHg})$ could induce the differentiation of periosteumderived mesenchymal stem cells (P-MSCs) toward the osteogenic phenotypes after the 7 days cultured with the help of osteogenic inductive medium. For healing cutaneous wounds, some reports have been demonstrated that high levels of negative pressure (approximately $-150-200 \mathrm{mmHg}$ ) may be efficient to induce macromechanical deformation of wounds and may be more favorable in soft tissue wounds [33, 34]. Therefore, we used $-150 \mathrm{mmHg}$ as the applied pressure in this study and proved that NPWT could induce BMSCs to differentiate into angiogensis related cells including pericytes, endothelial cells, and vessel smooth muscle cells, which are beneficial for the formation of granulation tissue in the absence of inductive medium. We hypothesized that this inductive therapeutic effect is due to the changed BMSCs' morphology with thicker appearance and more organized actin cytoskeleton caused by NPWT. In the vitro experiment, BMSCs exhibited a spindle-shaped morphology and stretched cytoskeleton under NPWT, which is consistent with the previous study [19]. This is a crucial finding because frequently there is a lack of sufficient stimulation within the wounds of patients to induce the transplanted BMSCs to differentiate into the desired cell types.

Particularly, hypoxia condition is beneficial for maintaining hMSCs in proliferating condition, especially in the late stage of hypoxia microenvironment such as 7 days. In addition, hMSCs would maintain their growth-rates even after reaching confluence and also exhibit differences in the cell and nuclear morphologies as well as accelerated ECM organization, leading to the better tissue regeneration [22]. Therefore, an optimized therapy that may serve as a stimulus to generate hypoxia condition and microenvironment would be helpful to enhance the viability of transplanted BMSCs. Erba et al. [21] have demonstrated that the NPWT treatment accelerates wound repair not only by a hypoxia driven well organized new vessels within the wound bed, but also by mechanical forces mediated activation of angiogenesis related cells proliferation. They concluded that the subatmospheric 

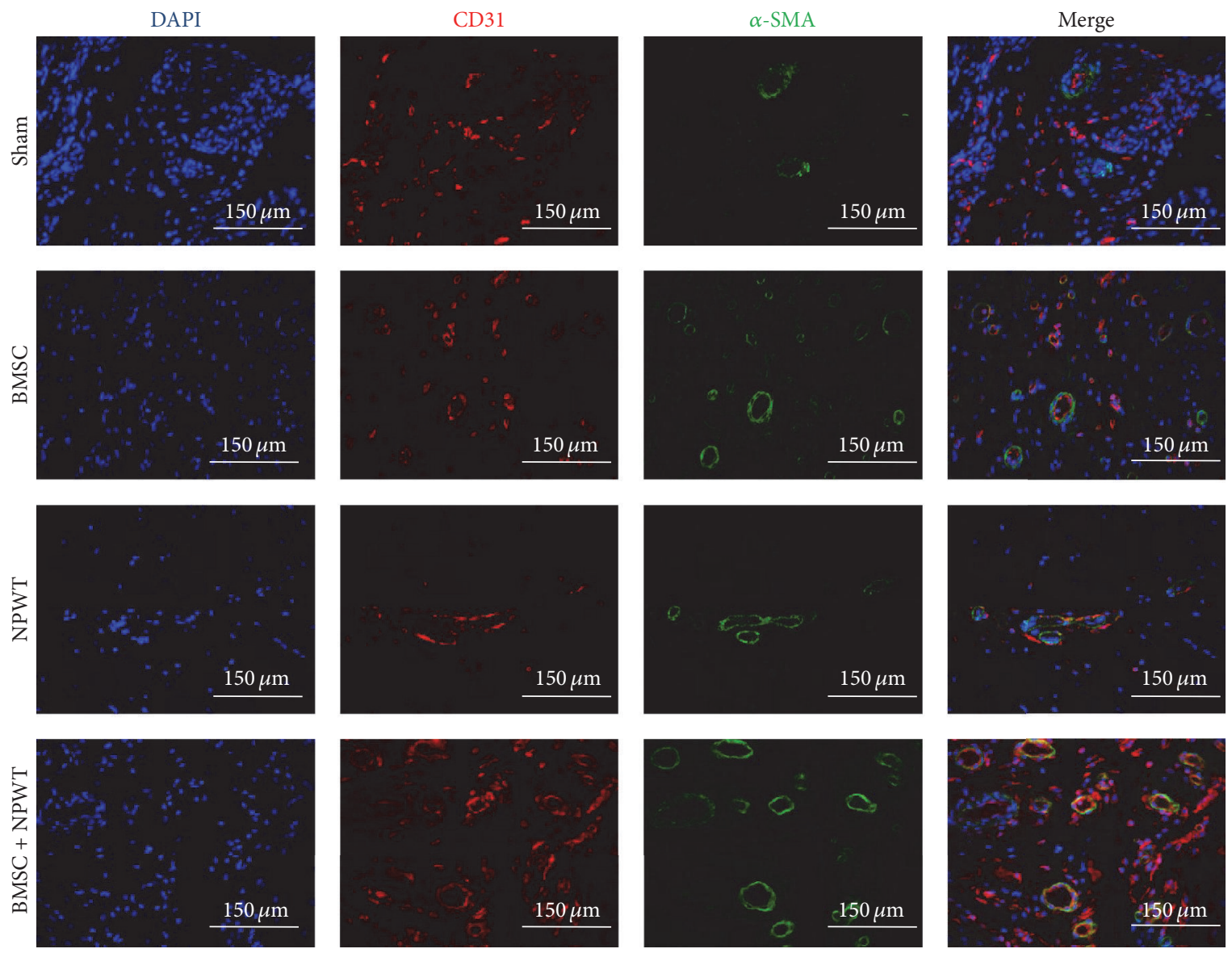

(a)

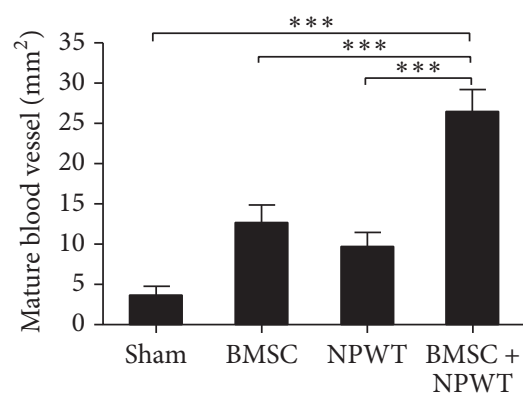

(b)

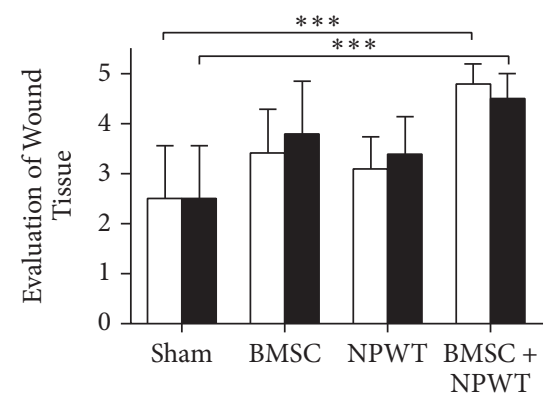

$\square$ Granulation Tissue Score

- Wound Maturity Score

(c)

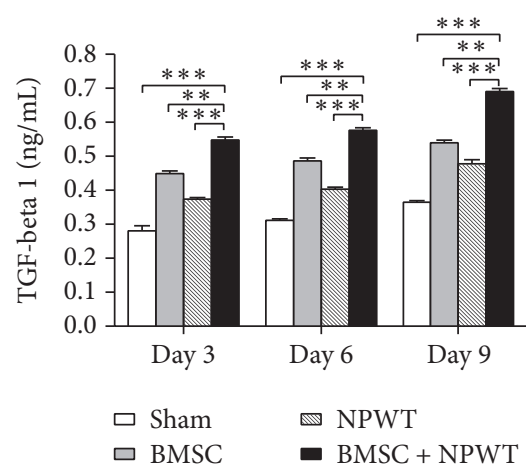

(d)

FIGURE 6: BMSC + NPWT accelerate the formation of mature vessel. (a) Immunofluorescence staining for CD31 and a-SMA. Red and green costaining represented mature blood vessels. Nuclei were stained with DAPI (blue). (b) Quantification of mature blood vessels. (c) Granulation tissue score and wound maturity score. (d) Concentration of TGF- $\beta_{1}$ within wounds among different groups. Data is given as the mean \pm SD, ${ }^{* *} p<0.01,{ }^{* * *} p<0.001$.

pressure wound therapy was capable of establishing a gradient hypoxia environment within wounds. In our study, both of in vitro and in vivo experiment showed enhanced activity of BMSCs under NPWT compared with transplanting cells alone, which supported the previous finding. Hence, we hypothesise that NPWT could generate a relative hypoxia microenvironment, stimulating transplanted BMSCs to maintain a better activity, leading to enhanced viability of the cells for further cutaneous repair.

Wound healing is a dynamic development that comprises the network among the extracellular matrix (ECM), growth factors, and various types of resident cells. It begins with the proliferation of fibroblasts generation of collagen fibers and angiogenesis, leading to granulation tissue, wound 


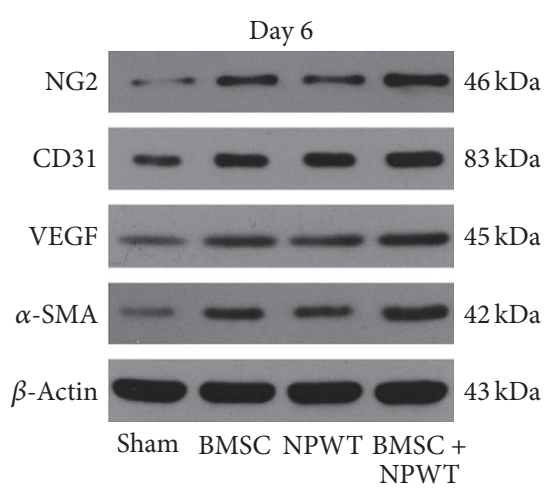

(a)

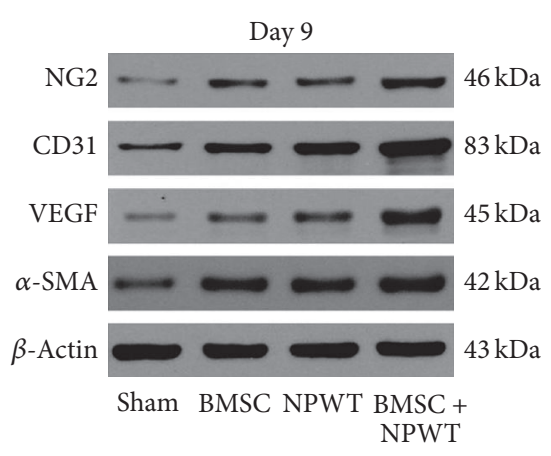

(c)

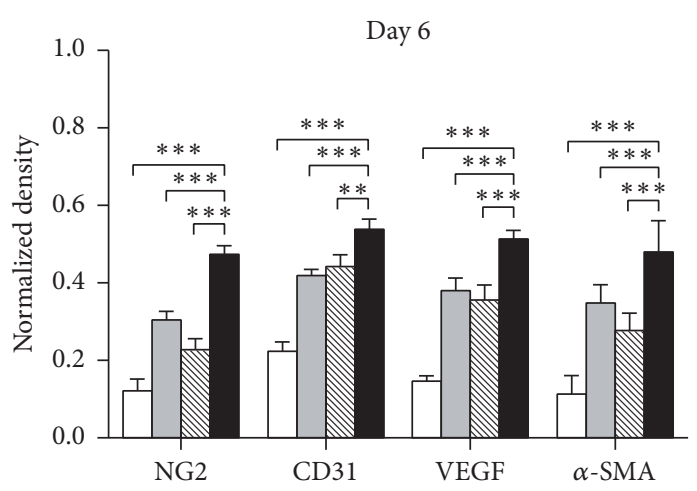

(b)

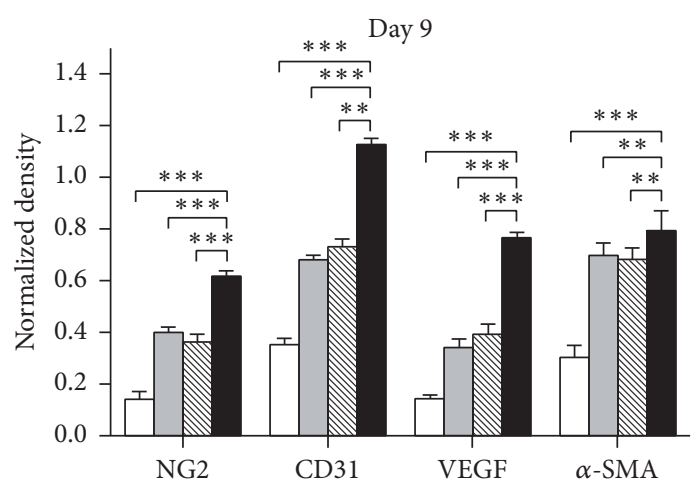

(d)
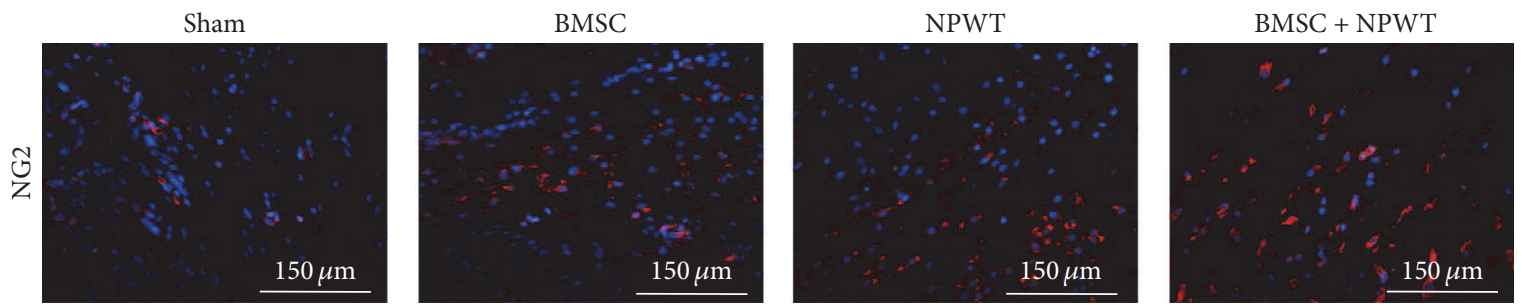

(e)

FIGURE 7: Assessment of angiogenesis related factors and cytokines. (a) Western blotting of NG2, VEGF, CD31, and $\alpha$-SMA protein expression within wounds among different groups on day 6. (b) Quantification of western blot results on day 6. (c) Western blotting of NG2, VEGF, CD31, and $\alpha$-SMA protein expression within wounds among different groups on day 9. (d) Quantification of western blot results on day 9. (e) Immunofluorescence staining of NG2 within wounds on day 9. Nuclei were stained with DAPI (blue). Data is given as the mean \pm SD, ${ }^{* *} p<0.01,{ }^{* * *} p<0.001$.

contraction, and epithelialization. Notably, vasculogenesis and angiogenesis are indispensable for wound healing. Angiogenesis consists of the sprouting and remodeling of the primitive blood vessels, followed by the stabilization of mural cells (e.g., pericytes for small vessels and smooth muscle cells for large vessels) [3]. The interaction of ECs and mural cells aids to stabilizing the microvessels, which is required for vessel maturation [35]. Therefore, the pericytes, ECs, and smooth muscle cells play significant roles in angiogenesis. In our study, the in vitro and the in vivo tests showed BMSC + NPWT enhanced the expression of NG2, CD31, VEGF, and $\alpha$-SMA, representing the activity of pericytes, ECs, and smooth muscle cells, respectively. Furthermore, we performed the immunohistochemical staining of CD31, a membrane-spanning protein expressed early in blood vessel development, to assess the newly formed vessels, and collagen IV, which plays an important role in ECM formation for wound healing [36]. Besides, the generation of mature blood vessels is characterized by the endothelial cells completely encircled by smooth muscle cells, which can be showed by CD31 and $\alpha$-SMA, respectively [37]. Hence, the costaining of CD31 and $\alpha$-SMA can be utilized to locate the mature blood vessels. The results of immunohistochemistry and immunofluorescence staining proved that treatment of the skin defects with BMSC + NPWT not only enhanced the number of newly formed blood vessels but also improved their maturity (Figures 5 and 6). Coupled with the western blotting and PCR results indicating the upregulated expression of NG2, CD31, VEGF, and $\alpha$-SMA (Figures 6 and 7), our findings demonstrated that BMSC + NPWT 

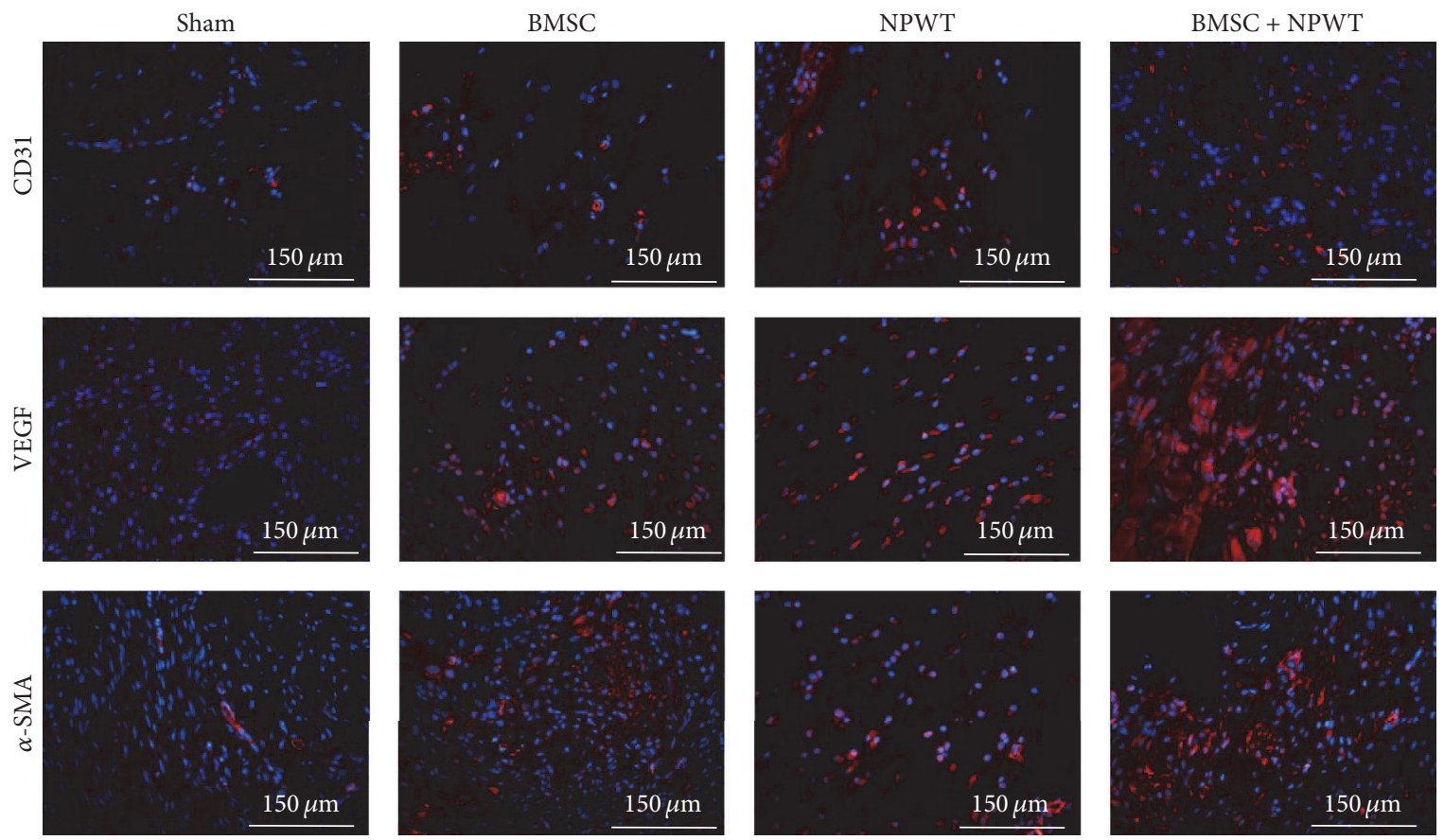

(a)

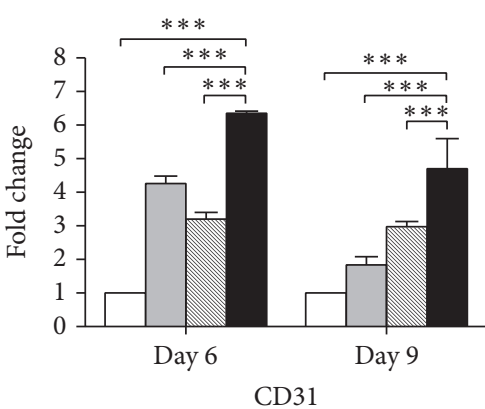

$$
\begin{array}{ll}
\square \text { Sham } & \text { NPWT } \\
\square \text { BMSC } & \text { BMSC + NPWT }
\end{array}
$$

(b)

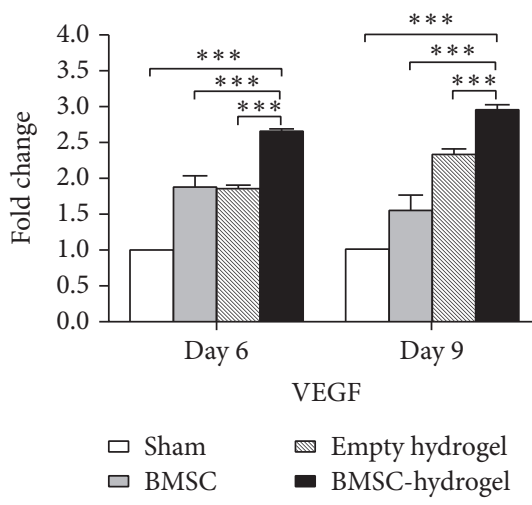

(c)

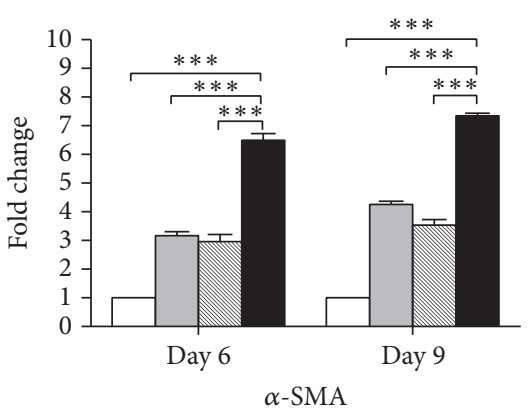

$$
\begin{aligned}
& \square \text { Sham } \quad \text { NPWT } \\
& \square \text { BMSC } \quad \text { BMSC + NPWT }
\end{aligned}
$$

(d)

FIGURE 8: Assessment of angiogenesis related factors and cytokines. (a) Immunofluorescence staining of CD31, VEGF, and $\alpha$-SMA within wounds among different groups on day 9. (b) RT-PCR results revealed more expression of CD31, VEGF, and $\alpha$-SMA in wounds treated with $\mathrm{BMSC}+\mathrm{NPWT}$ group compared to other three groups. Data is given as the mean $\pm \mathrm{SD},{ }^{* * *} p<0.001$.

could enhance the BMSC angiogenic capacity, resulting in accelerated wound healing and regeneration.

Currently, studies of cell-based treatment of complex wounds have largely focused on the use of MSCs transplanted topically, via injection around the edges of the wound directly $[38,39]$. The experimental study performed on rodent wound models and clinical trials of chronic wounds has demonstrated that MSCs can effectively and safely accelerate wound healing [40]. Since the isolation and propagation of MSCs is a relative simple process, this therapy is particularly of interest [41]. Additionally, the use of MSCs is with low clinical risk. For NPWT, it is widely used in wound care in adults, and there are even numbers of peer-reviewed case studies in pediatrics, reflecting its safety and effectiveness in the pediatric population [42]. Hence, the process using BMSCs and NPWT as a combinatory treatment would be feasible and simple on patients. Particularly, our findings can assist clinicians to treat the complex and chronic wounds with an alternative method instead of using traditional way such as changing gauze, which is time-saving and economical, eliminating the risk of potential immunogenicity risk and infection.

\section{Conclusion}

These findings demonstrate that the capacity of NPWT to enhance BMSC angiogenic property for cutaneous wound healing potentially by preserving the viability of the cells, stimulating, and inducing them to differentiate into the desired cells that are beneficial for angiogensis within 
wounds. This combinatory strategy is superior to either of cells transplantation and NPWT therapy alone, leading to the accelerated wound healing. Further optimization of the applicable parameter of NPWT and BMSCs may provide more benefits to clinical application.

\section{Competing Interests}

The authors have declared that there is no conflict of interests.

\section{Authors' Contributions}

Kangquan Shou and Yahui Niu contributed equally to this work.

\section{Acknowledgments}

This work was supported by Grants from the National Natural Science Foundation of China (Grant no. 81572163).

\section{References}

[1] A. J. Singer and R. A. F. Clark, "Cutaneous wound healing," New England Journal of Medicine, vol. 341, no. 10, pp. 738-746, 1999.

[2] C. Hrabchak, L. Flynn, and K. A. Woodhouse, "Biological skin substitutes for wound cover and closure," Expert Review of Medical Devices, vol. 3, no. 3, pp. 373-385, 2006.

[3] S. Zhao, L. Li, H. Wang et al., "Wound dressings composed of copper-doped borate bioactive glass microfibers stimulate angiogenesis and heal full-thickness skin defects in a rodent model," Biomaterials, vol. 53, pp. 379-391, 2015.

[4] A. J. Singer and R. A. F. Clark, "Cutaneous wound healing," The New England Journal of Medicine, vol. 341, no. 10, pp. 738-746, 1999.

[5] Y. Wu, L. Chen, P. G. Scott, and E. E. Tredget, "Mesenchymal stem cells enhance wound healing through differentiation and angiogenesis," STEM CELLS, vol. 25, no. 10, pp. 2648-2659, 2007.

[6] E. V. Badiavas and V. Falanga, "Treatment of chronic wounds with bone marrow-derived cells," Archives of Dermatology, vol. 139, no. 4, pp. 510-516, 2003.

[7] S. M. Bauer, L. J. Goldstein, R. J. Bauer, H. Chen, M. Putt, and O. C. Velazquez, "The bone marrow-derived endothelial progenitor cell response is impaired in delayed wound healing from ischemia," Journal of Vascular Surgery, vol. 43, no. 1, pp. 134-141, 2006.

[8] A. Keating, "Mesenchymal stromal cells," Current Opinion in Hematology, vol. 13, no. 6, pp. 419-425, 2006.

[9] A. B. Carvalho, L. F. Quintanilha, J. V. Dias et al., "Bone marrow multipotent mesenchymal stromal cells do not reduce fibrosis or improve function in a rat model of severe chronic liver injury," Stem Cells, vol. 26, no. 5, pp. 1307-1314, 2008.

[10] K. Bai, Y. Huang, X. Jia, Y. Fan, and W. Wang, "Endothelium oriented differentiation of bone marrow mesenchymal stem cells under chemical and mechanical stimulations," Journal of Biomechanics, vol. 43, no. 6, pp. 1176-1181, 2010.

[11] P. Zhang, J. Baxter, K. Vinod, T. N. Tulenko, and P. J. Di Muzio, "Endothelial differentiation of amniotic fluid-derived stem cells: synergism of biochemical and shear force stimuli," Stem Cells and Development, vol. 18, no. 9, pp. 1299-1308, 2009.
[12] J. Xu, X. Liu, J. Chen et al., "Simvastatin enhances bone marrow stromal cell differentiation into endothelial cells via notch signaling pathway," American Journal of Physiology-Cell Physiology, vol. 296, no. 3, pp. C535-C543, 2009.

[13] A. B. Faia-Torres, M. Charnley, T. Goren et al., "Osteogenic differentiation of human mesenchymal stem cells in the absence of osteogenic supplements: a surface-roughness gradient study," Acta Biomaterialia, vol. 28, pp. 64-75, 2015.

[14] C. M. Mouës, F. Heule, and S. E. R. Hovius, "A review of topical negative pressure therapy in wound healing: sufficient evidence?" The American Journal of Surgery, vol. 201, no. 4, pp. 544-556, 2011.

[15] M. T. Eginton, K. R. Brown, G. R. Seabrook, J. B. Towne, and R. A. Cambria, "A prospective randomized evaluation of negativepressure wound dressings for diabetic foot wounds," Annals of Vascular Surgery, vol. 17, no. 6, pp. 645-649, 2003.

[16] J. Apelqvist, D. G. Armstrong, L. A. Lavery, and A. J. M. Boulton, "Resource utilization and economic costs of care based on a randomized trial of vacuum-assisted closure therapy in the treatment of diabetic foot wounds," American Journal of Surgery, vol. 195, no. 6, pp. 782-788, 2008.

[17] O. Borgquist, E. Anesäter, E. Hedström, C. K. Lee, R. Ingemansson, and M. Malmsjö, "Measurements of wound edge microvascular blood flow during negative pressure wound therapy using thermodiffusion and transcutaneous and invasive laser Doppler velocimetry," Wound Repair and Regeneration, vol. 19, no. 6, pp. 727-733, 2011.

[18] E. A. Azzopardi, D. E. Boyce, W. A. Dickson et al., "Application of topical negative pressure (vacuum-assisted closure) to splitthickness skin grafts: a structured evidence-based review," Annals of Plastic Surgery, vol. 70, no. 1, pp. 23-29, 2013.

[19] R. P. Wilkes, A. K. McNulty, T. D. Feeley, M. A. Schmidt, and K. Kieswetter, "Bioreactor for application of subatmospheric pressure to three-dimensional cell culture," Tissue Engineering, vol. 13, no. 12, pp. 3003-3010, 2007.

[20] J. Zhu, A. Yu, B. Qi, Z. Li, and X. Hu, "Effects of negative pressure wound therapy on mesenchymal stem cells proliferation and osteogenic differentiation in a fibrin matrix," PLOS ONE, vol. 9, no. 9, Article ID e0107339, 2014.

[21] P. Erba, R. Ogawa, M. Ackermann et al., "Angiogenesis in wounds treated by microdeformational wound therapy," Annals of Surgery, vol. 253, no. 2, pp. 402-409, 2011.

[22] W. L. Grayson, F. Zhao, B. Bunnell, and T. Ma, "Hypoxia enhances proliferation and tissue formation of human mesenchymal stem cells," Biochemical and Biophysical Research Communications, vol. 358, no. 3, pp. 948-953, 2007.

[23] J. T. Hardwicke, J. Hart, A. Bell, R. Duncan, D. W. Thomas, and R. Moseley, "The effect of dextrin-rhEGF on the healing of fullthickness, excisional wounds in the (db/db) diabetic mouse," Journal of Controlled Release, vol. 152, no. 3, pp. 411-417, 2011.

[24] D. G. Armstrong and L. A. Lavery, "Negative pressure wound therapy after partial diabetic foot amputation: a multicentre, randomised controlled trial," The Lancet, vol. 366, no. 9498, pp. 1704-1710, 2005.

[25] E. Joseph, C. A. Hamori, S. Bergman, E. Roaf, N. F. Swann, and G. W. Anastasi, "A prospective randomized trial of vacuumassisted closure versus standard therapy of chronic nonhealing wounds," Wounds, vol. 12, no. 3, pp. 60-67, 2000.

[26] S. K. McCallon, C. A. Knight, J. P. Valiulus, M. W. Cunningham, J. M. McCulloch, and L. P. Farinas, "Vacuum-assisted closure versus saline-moistened gauze in the healing of postoperative 
diabetic foot wounds," Ostomy/Wound Management, vol. 46, no. 8, pp. 28-34, 2000.

[27] D. G. Armstrong, C. E. Attinger, A. J. M. Boulton et al., "Guidelines regarding negative wound therapy (NPWT) in the diabetic foot," Ostomy/Wound Management, vol. 50, no. 4, pp. 3S-27S, 2004.

[28] D. Kakagia, E. J. Karadimas, G. Drosos, A. Ververidis, G. Trypsiannis, and D. Verettas, "Wound closure of leg fasciotomy: comparison of vacuum-assisted closure versus shoelace technique. A randomised study," Injury, vol. 45, no. 5, pp. 890-893, 2014.

[29] G. Wilkin, S. Khogali, S. Garbedian et al., "Negative-pressure wound therapy after fasciotomy reduces muscle-fiber regeneration in a pig model," The Journal of Bone \& Joint SurgeryAmerican Volume, vol. 96, no. 16, pp. 1378-1385, 2014.

[30] S.-L. Chen, W.-W. Fang, F. Ye et al., "Effect on left ventricular function of intracoronary transplantation of autologous bone marrow mesenchymal stem cell in patients with acute myocardial infarction," The American Journal of Cardiology, vol. 94, no. 1, pp. 92-95, 2004.

[31] Y. Wu, R. C. H. Zhao, and E. E. Tredget, "Concise review: bone marrow-derived stem/progenitor cells in cutaneous repair and regeneration," STEM CELLS, vol. 28, no. 5, pp. 905-915, 2010.

[32] S. Bajada, P. E. Harrison, B. A. Ashton, V. N. Cassar-Pullicino, N. Ashammakhi, and J. B. Richardson, "Successful treatment of refractory tibial nonunion using calcium sulphate and bone marrow stromal cell implantation," Journal of Bone \& Joint Surgery B, vol. 89, no. 10, pp. 1382-1386, 2007.

[33] T. Isago, M. Nozaki, Y. Kikuchi, T. Honda, and H. Nakazawa, "Effects of different negative pressures on reduction of wounds in negative pressure dressings," The Journal of Dermatology, vol. 30, no. 8, pp. 596-601, 2003.

[34] M. Malmsjö, R. Ingemansson, R. Martin, and E. Huddleston, "Negative-pressure wound therapy using gauze or open-cell polyurethane foam: similar early effects on pressure transduction and tissue contraction in an experimental porcine wound model," Wound Repair and Regeneration, vol. 17, no. 2, pp. 200205, 2009.

[35] H. Gerhardt and C. Betsholtz, "Endothelial-pericyte interactions in angiogenesis," Cell and Tissue Research, vol. 314, no. 1, pp. 15-23, 2003.

[36] R. Huang, W. Li, X. Lv et al., "Biomimetic LBL structured nanofibrous matrices assembled by chitosan/collagen for promoting wound healing," Biomaterials, vol. 53, pp. 58-75, 2015.

[37] M. J. Morykwas, B. J. Faler, D. J. Pearce, and L. C. Argenta, "Effects of varying levels of subatmospheric pressure on the rate of granulation tissue formation in experimental wounds in swine," Annals of Plastic Surgery, vol. 47, no. 5, pp. 547-551, 2001.

[38] J. M. Sorrell and A. I. Caplan, "Topical delivery of mesenchymal stem cells and their function in wounds," Stem Cell Research \& Therapy, vol. 1, article 30, 2010.

[39] H. Ravari, D. Hamidi-Almadari, M. Salimifar, S. Bonakdaran, M. R. Parizadeh, and G. Koliakos, "Treatment of non-healing wounds with autologous bone marrow cells, platelets, fibrin glue and collagen matrix," Cytotherapy, vol. 13, no. 6, pp. 705-711, 2011.

[40] V. Falanga, S. Iwamoto, M. Chartier et al., "Autologous bone marrow-derived cultured mesenchymal stem cells delivered in a fibrin spray accelerate healing in murine and human cutaneous wounds," Tissue Engineering, vol. 13, no. 6, pp. 1299-1312, 2007.

[41] J. C. Ra, I. S. Shin, S. H. Kim et al., "Safety of intravenous infusion of human adipose tissue-derived mesenchymal stem cells in animals and humans," Stem Cells and Development, vol. 20, no. 8, pp. 1297-1308, 2011.

[42] M. Baharestani, I. Amjad, K. Bookout et al., "V.A.C. ${ }^{\circledR}$ therapy in the management of paediatric wounds: clinical review and experience," International Wound Journal, vol. 6, no. 1, pp. 1-26, 2009. 


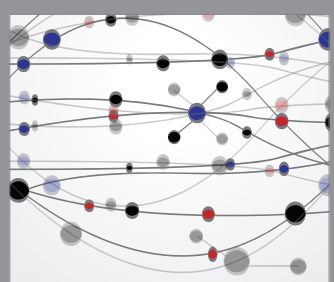

The Scientific World Journal
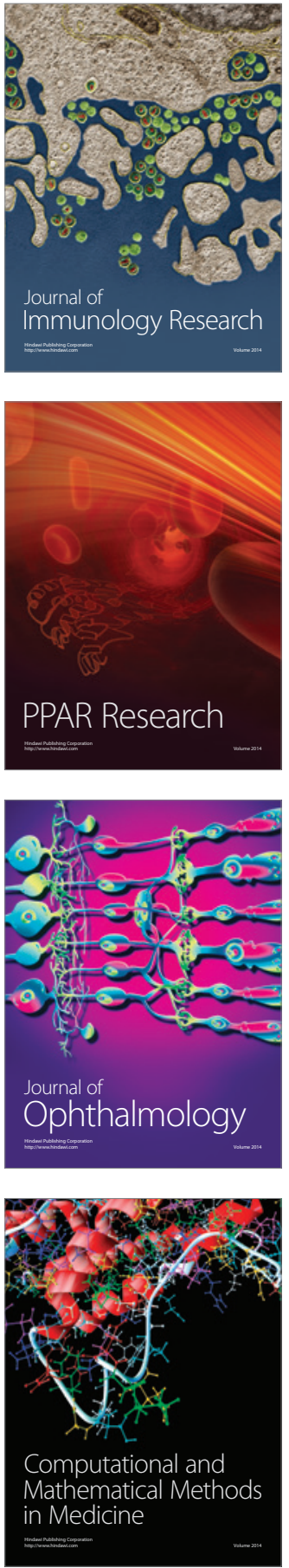

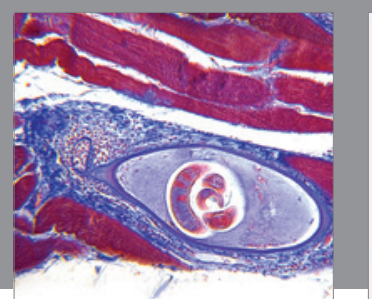

Gastroenterology Research and Practice
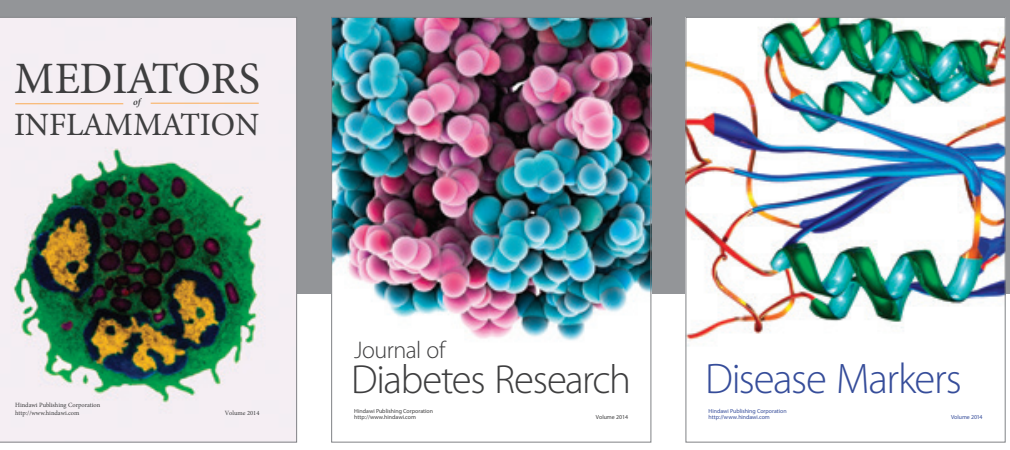

Disease Markers

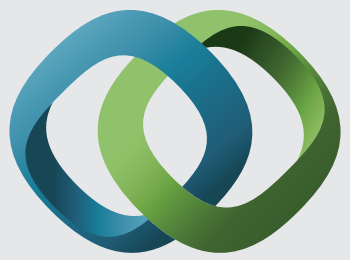

\section{Hindawi}

Submit your manuscripts at

https://www.hindawi.com
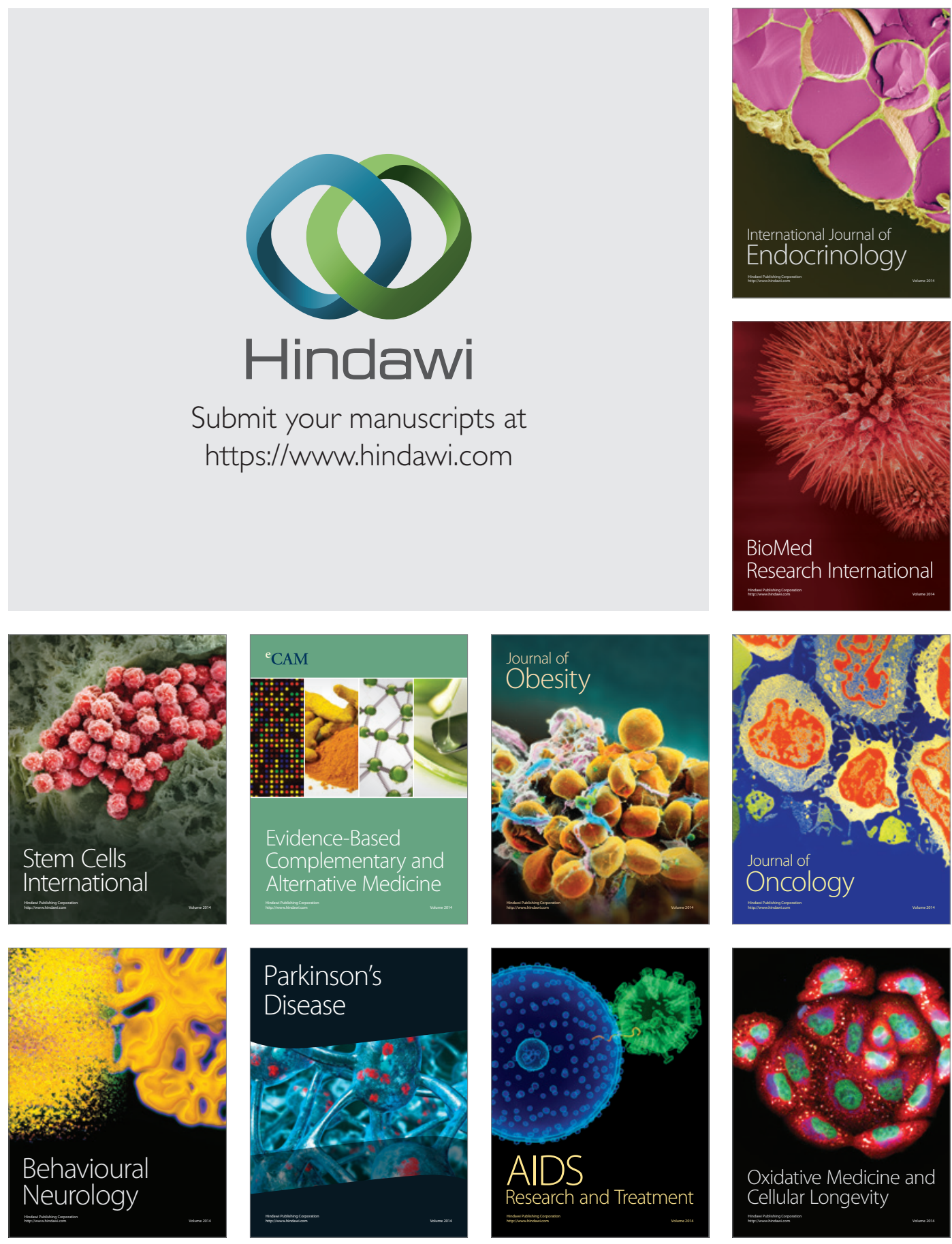